\title{
Strategies for the prevention of periodontal disease and its impact on general health in Latin America. Section III: Prevention
}

\section{Andrés Duque DUQUE(a) \\ Zilson MALHEIROS $(b, c)$ \\ Bernal STEWART ${ }^{(b, c)}$ iD \\ Hugo Jorge ROMANELLI(d)}

\footnotetext{
(a) Universidad CES, Faculty of Dentistry, Department of Periodontics, Medellin, Antioquia, Colombia.

(b)Latin American Oral Health Association LAOHA, São Paulo, SP, Brazil.

(c) Colgate-Palmolive Company, Piscataway, NJ, USA.

(d) Maimónides University, Faculty of Health Sciences, Department of Periodontics, Buenos Aires, Argentina.
}

Declaration of Interests: The authors certify that they have no commercial or associative interest that represents a conflict of interest in connection with the manuscript.

Corresponding Author:

Andrés Duque Duque

E-mail: aduqued@ces.edu.co

\begin{abstract}
Dental plaque removal and the understanding of risk factors, risk indicators and social determinants are important components in the prevention of periodontal disease. Periodontal diseases and dental caries are largely preventable conditions, but require a "common risk factor approach" with non-communicable diseases with the purpose of improving their prevention and control, and positive impact on health. The aim of this consensus was to identify the evidence and gaps in periodontal prevention in Latin American, and to propose individual and collective recommendations for the population, health professionals, dental practice and government. The prevention of periodontal diseases in Latin America has mainly been focused on oral hygiene instruction, use of toothbrushes and interproximal devices, but in some patients, it is necessary to use adjuncts to these measures, such as antimicrobial and/or probiotic products that are backed by broad scientific evidence. Some evidence has shown that there are inadequate knowledge, attitudes and practices among patients, dentist and other health professionals. The prevention of periodontal diseases and caries should be adopted as a healthy lifestyle routine, because of their local and systemic effects. Recently, new empowerment strategies have been proposed in order to generate behavioral changes. Periodontal diseases can often be prevented, or controlled by joined efforts between government health systems, scientific associations, universities, health professionals, private companies and communities. In conclusion, the relations between periodontal diseases, caries, healthy lifestyles and NCD's offer an ideal opportunity to change Latin American prevention strategies at both the individual level and population levels.
\end{abstract}

Keywords: Periodontal Diseases; Public Health; Latin America.

\section{Introduction}

The International Dental Federation (FDI) has defined oral health as being multi-faceted and it includes the ability to speak, smile, smell, taste, touch, chew, swallow and convey a range of emotions through facial expressions with confidence and without pain, discomfort or disease of the craniofacial complex. ${ }^{1}$ Periodontal diseases are chronic multi-factorial diseases 
initiated by bacterial microorganisms. They produce infectious and inflammatory reactions that impact the body locally and systemically. There is evidence that periodontal diseases are linked to systemic conditions and their risk factors are shared with caries and non-communicable diseases (NCDs). ${ }^{2}$ Therefore, the concept of oral health should also include "oral health without negative consequences on general health". The prevalence of periodontal diseases is related to plaque biofilm and risk factors such as smoking and diabetes. In addition, periodontal diseases may be associated with other risk indicators, such as: metabolic syndrome, hereditary factors, behavioral factors, compliance during periodontal maintenance, stress, and obesity., ${ }^{3,4}$ Dental plaque removal and the understanding of risk factors, risk indicators and social determinants are important components in the prevention of periodontal diseases. Health professionals should be involved in programs for the prevention of caries and periodontal diseases because they could initiate or exacerbate the development of NCDs. ${ }^{5,6,7,8,9,10}$ Periodontal diseases and dental caries are largely preventable bacterial infections that require a "common risk factor approach" with NCDs with the purpose of their prevention and control. ${ }^{5,11}$

At present preventive approaches require individual and collective measures, on the understanding that they seek different goals and impacts; in Latin America the dental profession faces three major challenges, which include: education on the importance of periodontal health; empowerment of patients through the incorporation of healthy lifestyles; and the development of new strategies and technologies to promote adequate oral healthcare habits. The aim of this consensus is 1) to identify the evidence and gaps in periodontal prevention in Latin American, and 2) to propose individual and collectives recommendations for the population, community, health professionals, dental practice and government with the purpose of improving prevention strategies.

\section{Evidence for the population (Individual-level measures)}

The prevention of periodontal diseases in Latin America has mainly been focused on oral hygiene instruction for reducing dental plaque. Although clinical evidence has shown that mechanical oral hygiene is fundamental to prevent periodontal diseases, it is important to highlight that optimal control is not always achieved. ${ }^{12}$ Despite the short-term efficacy of plaque reduction in clinical studies, these positive results have not been corroborated in Latin American prevalence studies. ${ }^{13,14,15}$ Some evidence has shown that there is inadequate knowledge, as well as attitudes and practices in Latin America relative to diagnosis, prevention, risk factors and systemic consequences. ${ }^{16,17}$ In addition, some people fear the diagnosis and treatment of periodontal diseases (dental phobia) and are negligent with regard to prevention, maintenance and early detection. ${ }^{18}$ Therefore, the actions of individuals are governed by the personal misconceptions about their dental needs. An individual's perception of control is regarded as an important socio-behavioral factor in general. There is some evidence that having a strong internal perception of control contributes to the prevention of dental caries and periodontal diseases. ${ }^{5}$ Limited qualitative research has been done in Latin America to investigate what patients think about the term "dental plaque". There is evidence of lack of recognition of the term "periodontal diseases" as a gingival oral condition. A clinical sign of periodontal diseases such as gingival bleeding is not considered a health problem by many patients, and they are unaware of the health implications of the infectious and inflammatory characteristics of periodontal diseases. ${ }^{16}$

Epidemiological data relative to oral health habits and behavior are scarce and disclose only limited information on adult subjects. A multicenter study in three South American cities regarding oral health behavior showed that $84.2 \%$ of the participants who brushed twice a day or more, $66 \%$ never cleaned interproximally, and only $39.6 \%$ sought a preventive dental checkup at least once a year. ${ }^{19}$ More years of education were significantly associated with higher frequency of tooth brushing, use of dental floss, regular dental checkups, less gingival bleeding and lower plaque scores. Low frequency of interdental cleaning and no regular preventive dental care were 
associated with the presence of more plaque and gingival inflammation.

The majority of studies on prevention of periodontal diseases have not taken into account behavioral change models and patient empowerment (by incorporating oral health into a healthy lifestyle) such as: COM-B (Capability, Opportunity and Motivation-Behavior) ${ }^{20}$, Patient-Centered Care (5 key components of PCC: connection, attitude, communication, empowerment and feeling valued) ${ }^{21}$ and Empathy-Based Medicine. ${ }^{22}$ Additionally, a new health perspective included a holistic, global and integrative approach (systems biology and digital revolution) called Proactive P4 medicine (P4: Predictive, Preventive, Personalized, Participatory). ${ }^{23,24} \mathrm{~A}$ major oral health challenge will be to promote proactive strategies in patients and the community. There may possibly be different opportunities and oral hygiene behaviors when the various countries of Latin America are compared at both individual and collective levels. In this sense, the key to success will depend on the collaborative research and working networks. Positive experiences observed in one place could be replicated in other places. In addition, this requires the effective use of information technologies, human social networks, social networks on the Internet and new education strategies.

\section{Recommendations}

a. It is necessary to promote educational strategies for dental caries, periodontal diseases and NCDs prevention as a healthy lifestyle in different patient groups and communities (children and adolescents, smokers and patients with systemic diseases or disabilities);

b. It is necessary to promote positive attitudes and changes in behavior relative to periodontal and dental caries prevention and common risk factors with NCDs, through internationally proposed models and risk profile tools;

c. It is necessary to promote new empowerment strategies to modify oral health habits based on patient knowledge, attitudes, practices, abilities and self-monitoring.

\section{Evidence for dental practice and health professionals}

A systematic review on professional mechanical dental plaque removal in primary prevention has indicated its effectiveness when it was complemented with oral health instructions and this procedure has been useful in maintenance programs. The effectiveness of periodontal disease prevention depends on motivation, knowledge, patient empowerment, provision of adequate oral hygiene instruction, type of oral hygiene aids and patient dexterity. ${ }^{12,17,25,26}$ Evidence has shown that brushing associated with flossing can control dental biofilm buildup when performed adequately and systematically, at regular intervals. ${ }^{25}$ However, in Latin America most of the population has presented low adherence to flossing and interdental devices. ${ }^{27}$ Provision of oral hygiene instructions alone led to small reduction in dental plaque and gingivitis. A single exercise of manual brushing or using a power toothbrush has been associated with $42 \%$ and $46 \%$ of the reduction of dental plaque respectively, but there was little evidence of the clinical impact on gingival inflammation. The key is therefore to train regional health professionals and dental hygienists on how to educate and motivate patients on the adequate selection of techniques and tactics, since there is not a single one that is indicated for the entire population, given variations in manual dexterity, anatomical types of oral cavities, and psycho-social backgrounds. Regarding the latter, the importance of dental hygienists must be highlighted with regard to accompanying patients in this process, in the role of health coaches and guides, going beyond their traditional, very passive role in Latin America, which has been limited to primary prevention.

Interproximal cleaning is essential in order to maintain interproximal gingival health. Moderate evidence has suggested that as an adjunct to tooth brushing the use of interdental brushes provided higher levels of plaque reduction than manual tooth brushing alone, but there is conflicting and scare evidence on the effectiveness in reducing inflammation and clinical relevance. Other interproximal devices (flossing, oral irrigators and wood sticks) showed weak evidence of reducing 
inflammation..$^{25}$ The use of chemical antiplaque agents in mouthwashes or dentifrices provides improvement in plaque and gingival inflammation reduction. Chemical plaque control should be regarded as a needed related treatment, not as a substitute for mechanical dental plaque control. ${ }^{26}$ Mouthwashes are effective in the reduction of dental plaque and gingivitis provided that they are used in combination with mechanical control. The selection of the mode of use is dependent on the active agent, cost, patient preference and compliance..$^{25}$ Among the contemporary strategies are prebiotics and probiotics used for the prevention of gingivitis, which appear to modulate the oral microbioma and decrease inflammatory processes. ${ }^{28}$ The use of adjunct products supported by broad scientific evidence, therefore, seems to be an interesting strategy from a public health stance, given the difficulty in changing the social and behavioral conditions of the population.

Health professionals receive limited information and documentation on the diagnosis, prevention, systemic consequences and common risk factors for dental caries, periodontal diseases and NCD's. Periodontal prevention also depends on interdisciplinary relationships with other medical and dental specialties. Emerging evidence has shown the lack of knowledge of some health professionals in Latin America with reference to periodontal diseases and their oral and systemic consequences. Furthermore, dentists have not participated sufficiently in healthy lifestyle programs such as prevention of tobacco use, diabetes and cardiovascular prevention programs, etc.

\section{Recommendations - Strategies for dental practice and health professionals}

a. It is important for dental professional to be acquainted with agents, products and devices to enable them to evaluate their effectiveness and adverse effects according to guidelines and future research. (Evaluate clinical impact of new technologies: dentifrices with active ingredients, toothbrushes, interdental brushes, flossing, mouth rinses and probiotics); b. It is essential to teach dental students and health professionals about the importance of dental biofilm control, risk factor evaluation, patient empowerment strategies and methods to change behavior;

c. It is necessary to change the role of the health professionals in the prevention and control of risk factors for periodontal diseases together with dental caries and NCDs (common risk factors approach);

d. It is necessary to propose common shared strategies between the periodontal scientific associations in Latin America and medical and patient associations;

e. It is necessary to promote technological strategies with the aim of motivating self-care and establishing agreements with different patient groups such as diabetic or cardiovascular patient associations;

f. Health professionals in Latin America require preventive guidelines and training that includes a common risk factor approach, behavioral change and patient empowerment strategies.

\section{Evidence for public health prevention in Latin America}

The integration of biological systems with the digital revolution suggests that treating patients in a more personalized way might be the best option, but from a population perspective this increases costs considerably. In this sense, individuals can be phenotypically characterized according to their risk factors, risk indicators and health determinants. ${ }^{23,24}$ It is necessary to consider the barriers that impede the implementation of preventive measures; in Latin America the low level of proactive involvement of governments is a factor that interferes in the decision-making process. Partnerships between universities, industry and government support are a critical pathway to produce knowledge and cooperation, which may include subsidies and supply of oral hygiene products. Considering secondary prevention, concepts need to be broadened in education and minimize interventions (e.g., professional elimination of biofilm). Most 
countries have a formal framework for programs to prevent chronic diseases such as cancer and diabetes, but these programs do not include oral cavity. In this sense, it is necessary to include the most common oral diseases in government prevention programs. Consideration should be given to the participation of oral care professionals in the control and prevention of smoking, recommendation on medical and health products. Considerations should also be given to incorporating measures and laboratory test in dental office, such as measuring waist circumference and glucose level, among others. Dentists and Oral Healthcare professionals can play a fundamental role in the cessation of smoking and possibly in reducing the risk of NCD's. The prevention of oral diseases is a preponderant issue that should not be in the hands dentists only, but also of other health professionals. This must also be taken into account when training dentists so they are motivated to work in a multidisciplinary way.

Periodontal diseases can often be prevented, reduced or controlled by joint efforts between government health systems, scientific associations, universities, health professionals, private companies, non-governmental organizations (NGOs) and communities. The third goal of sustainable development objectives established by the United Nations is the search for wellbeing and a healthy life in the population and a control of risk factors in developing countries. It is necessary to evaluate socio-biological interactions in periodontal diseases and models that may help to develop a better understanding of the causes of oral health inequalities and implicate the importance of addressing social determinants of oral health in innovative public health interventions. A prerequisite for properly implementing a preventive program directed towards periodontal diseases seems to be a well-organized public/oral health care system. To maximize cost-effectiveness, prevention of periodontal diseases should be based on predictive and risk models and the preventive strategy should be chosen based on risk evaluation. Health systems should put more work into recognition of the disease, its systemic consequences and risk factors. ${ }^{17,27,29,30,31}$

\section{Recommendations for public health prevention}

a. It is necessary to strengthen public policies to integrate prevention of oral diseases (dental caries and periodontal diseases) and NCD's;

b. It is necessary to establish alliances between dental associations, governmental and non-governmental organizations (policymakers and stakeholders), and health systems to emphasize the replacement of Oral Health Programs by Oral Health Policies. It is suggested that such policies should prioritize the concept of "Whole Mouth Health", focused on comprehensive care. This concept is an essential component for the general health of the human organism;

c. It is necessary to evaluate socio-biological interactions in periodontal diseases and models that may help to develop a better understanding of the causes of oral health inequalities and also implicate the importance of addressing the social determinants of oral health in innovative public health interventions;

d. It is necessary to promote massive campaigns to improve knowledge, attitudes and practices with reference to periodontal diseases in social networks, patient associations (e-patients) and the media.

\section{Conclusions and future perspectives for Latin America}

Dental plaque reduction represents the main component in the prevention and control of periodontal diseases, but new evidence and research is needed to evaluate the implementation of new strategies to improve education, empowerment and the acquisition of good oral health habits and healthy lifestyles by patients and the community.

There are two main preventive approaches: a preventive approach at the individual level centered on the patient; and a preventive approach at the level of the population / community that requires the proactive participation of the government in decision-making. The relations between periodontal 
diseases, caries, healthy lifestyles and NCD's offer an ideal opportunity to change prevention strategies at both the individual and population levels. Therefore, new preventive models should include the promotion of periodontal health as a healthy lifestyle. Each of the recommendations proposed in this consensus should be evaluated at the individual and / or population level with different approaches and strategies according to the particular circumstances in each Latin American country. Successful experiences should be shared among different countries for implementation in another context with the goal of improving oral health throughout the Latin American population.

\section{Acknowledgments}

This paper was prepared for the consensus meeting titled "Periodontal disease and its impact on general health in Latin America - Latin American Consensus", promoted by the Latin American Oral Health Association (LAOHA) and Colgate Palmolive Co. with participation of experts from the region, including representatives from Periodontal Societies of Latin America. All participants had the opportunity to review the content, and eventually make their own contributions. Consensus Report was based on this paper. The authors point out that they have no conflicts of interest.

\section{References}

1. Glick M, Williams DM, Kleinman DV, Vujicic M, Watt RG, Weyant RJ. A new definition for oral health developed by the FDI World Dental Federation opens the door to a universal definition of oral health. Br Dent J. 2016 Dec;147(12):915-7. 10.1016/i.adaj.2016.10.001

2. Tonetti MS, Eickholz P, Loos BG, Papapanou P, Velden U, Armitage G, et al. Principles in prevention of periodontal diseases: consensus report of group 1 of the 11th European Workshop on Periodontology on effective prevention of periodontal and peri-implant diseases. J Clin Periodontol. 2015 Apr;42 Suppl 16:S5-11. https://doi.org/10.1111/icpe.12368

3. Genco RJ, Borgnakke WS. Risk factors for periodontal disease. Periodontol 2000.2013 Jun;62(1):59-94. https://doi.org/10.1111/i.1600-0757.2012.00457.x

4. Knight ET, Liu J, Seymour GJ, Faggion CM Jr, Cullinan MP. Risk factors that may modify the innate and adaptive immune responses in periodontal diseases. Periodontol 2000. 2016 Jun;71(1):22-51. https://doi.org/10.1111/prd.12110

5. Jepsen S, Blanco J, Buchalla W, Carvalho JC, Dietrich T, Dörfer C, et al. Prevention and control of dental caries and periodontal diseases at individual and population level: consensus report of group 3 of joint EFP/ORCA workshop on the boundaries between caries and periodontal diseases. J Clin Periodontol. 2017 Mar;44 Suppl 18:S85-93. https://doi.org/10.1111/icpe.12687

6. Sanz M, Ceriello A, Buysschaert M, Chapple I, Demmer RT, Graziani F, et al. Scientific evidence on the links between periodontal diseases and diabetes: consensus report and guidelines of the joint workshop on periodontal diseases and diabetes by the International Diabetes Federation and the European Federation of Periodontology. J Clin Periodontol. 2018 Feb;45(2):138-49. https://doi.org/10.1111/icpe.12808

7. Ramírez JH, Arce RM, Contreras A. Periodontal treatment effects on endothelial function and cardiovascular disease biomarkers in subjects with chronic periodontitis: protocol for a randomized clinical trial. Trials. 2011 Feb;12:46. https://doi.org/10.1186/1745-6215-12-46

8. Jaramillo A, Contreras A, Lafaurie GI, Duque A, Ardila CM, Duarte S, et al. Association of metabolic syndrome and chronic periodontitis in Colombians. Clin Oral Investig. 2017 Jun;21(5):1537-44. https://doi.org/10.1007/s00784-016-1942-9

9. Chambrone L, Foz AM, Guglielmetti MR, Pannuti CM, Artese HP, Feres M, et al. Periodontitis and chronic kidney disease: a systematic review of the association of diseases and the effect of periodontal treatment on estimated glomerular filtration rate. J Clin Periodontol. 2013 May;40(5):443-56. https://doi.org/10.1111/jcpe.12067

10. Flores MF, Montenegro MM, Furtado MV, Polanczyk CA, Rösing CK, Haas AN. Periodontal status affects C-reactive protein and lipids in patients with stable heart disease from a tertiary care cardiovascular clinic. J Periodontol. 2014 Apr;85(4):545-53. https://doi.org/10.1902/jop.2013.130255

11. Niederman R, Feres M, Ogunbodede E. Dentistry. In: Debas HT, Donkor P, Gawande A, Jamison DT, Kruk ME, Mock CN, editors. Essential surgery: disease control priorities. 3rd ed. Washington, DC: The International Bank for Reconstruction and Development; 2015. Vol. 1.

12. Rode SM, Gimenez X, Montoya VC, Gómez M, Blanc SL, Medina M, et al. Daily biofilm control and oral health: consensus on the epidemiological challenge_Latin American Advisory Panel. Braz Oral Res. 2012;26(spel Suppl 1):133-43. https://doi.org/10.1590/S1806-83242012000700020

13. Carvajal P, Gómez M, Gomes S, Costa R, Toledo A, Solanes F, et al. Prevalence, severity, and risk indicators of gingival inflammation in a multi-center study on South American adults: a cross sectional study. J Appl Oral Sci. 2016 Sep-Oct;24(5):524-34. https://doi.org/10.1590/1678-775720160178 
14. Murillo G, Vargas MA, Castillo J, Serrano JJ, Ramirez GM, Viales JH, et al. Prevalence and severity of plaque-induced gingivitis in three Latin American cities: Mexico City-Mexico, Great Metropolitan Area-Costa Rica and Bogota-Colombia. Odovtos; 2018 May-Aug;20(2):91-102. https://doi.org/10.15517/ijds.v0i0.32451

15. Elías-Boneta AR, Toro MJ, Rivas-Tumanyan S, Rajendra-Santosh AB, Brache M, Collins C JR. Prevalence, severity, and risk factors of gingival inflammation in Caribbean adults: a multi-city, cross-sectional study. P R Health Sci J. 2018 Jun;37(2):115-23.

16. Duque A, Cuartas C, Muñoz C, Salazar C, Sanchez Y. Nivel de conocimeinto sobre enfermedad periodontal en una muestra de empleados en Medellin. Revista CES Odontologia. 2011;24(2):43-7.

17. Carvajal P. Enfermedades periodontales como un problema de salud pública: el desafío del nivel primario de atención en salud. Rev Clín Periodoncia Implantol Rehabil Oral. 2016;9(2):177-83. https://doi.org/10.1016/i.piro.2016.07.001

18. Heidari E, Andiappan M, Banerjee A, Newton JT. The oral health of individuals with dental phobia: a multivariate analysis of the Adult Dental Health Survey, 2009. Br Dent J. 2017 Apr;222(8):595-604. https://doi.org/10.1038/sj.bdj.2017.361

19. Gómez MV, Toledo A, Carvajal P, Gomes SC, Costa RS, Solanes F, et al. A multicenter study of oral health behavior among adult subjects from three South American cities. Braz Oral Res. 2018;32(0):e22. https://doi.org/10.1590/1807-3107bor-2018.vol32.0022

20. Newton JT, Asimakopoulou K. Behavioral models for periodontal health and disease. Periodontol 2000. 2018 Oct;78(1):201-11. https://doi.org/10.1111/prd.12236

21. Mills I, Frost J, Cooper C, Moles DR, Kay E. Patient-centred care in general dental practice--a systematic review of the literature. BMC Oral Health. 2014;14:64. https://doi.org/10.1186/1472-6831-14-64

22. Howick J, Rees S. Overthrowing barriers to empathy in healthcare: empathy in the age of the Internet. J R Soc Med. 2017 Sep;110(9):352-7. https://doi.org/10.1177/0141076817714443

23. Hood L, Flores M. A personal view on systems medicine and the emergence of proactive P4 medicine: predictive, preventive, personalized and participatory. N Biotechnol. 2012 Sep;29(6):613-24. https://doi.org/10.1016/i.nbt.2012.03.004

24. Kornman KS, Giannobile WV, Duff GW. Quo vadis: what is the future of periodontics? How will we get there? Periodontol 2000.2017 Oct;75(1):353-71. https://doi.org/10.1111/prd.12217

25. Chapple IL, Van der Weijden F, Doerfer C, Herrera D, Shapira L, Polak D, et al. Primary prevention of periodontitis: managing gingivitis. J Clin Periodontol. 2015 Apr;42 Suppl 16:S71-6. https://doi.org/10.1111/icpe.12366

26. Axelsson P, Albandar JM, Rams TE. Prevention and control of periodontal diseases in developing and industrialized nations. Periodontol 2000. 2002;29(1):235-46. https://doi.org/10.1034/j.1600-0757.2002.290112.x

27. Morales A, Bravo J, Baeza M, Werlinger F, Gamonal J. Las enfermedades periodontales como enfermedades crónicas no transmisibles: cambios en los paradigmas. Rev Clín Periodoncia Implantol Rehabil Oral. 2016;9(2):203-7. https://doi.org/10.1016/i.piro.2016.07.004

28. Montero E, Iniesta M, Rodrigo M, Marín MJ, Figuero E, Herrera D, et al. Clinical and microbiological effects of the adjunctive use of probiotics in the treatment of gingivitis: A randomized controlled clinical trial. J Clin Periodontol. 2017 Jul;44(7):708-16. https://doi.org/10.1111//cpe.12752

29. Contreras Rengifo A. La promoción de la salud general y la salud oral: una estrategia conjunta. Rev Clín Periodoncia Implantol Rehabil Oral. 2016;9(2):193-202. https://doi.org/10.1016/i.piro.2016.07.003

30. Romanelli H. About the Gum Health Day: periodontal health is possible. Rev Asoc Odontol Argentina. 2018 Mar;106(1):1-4.

31. Duque A, Tirado M, Arbeláez C, García S. Conocimientos y actitudes sobre la posible asociación de la periodontitis como factor de riesgo de algunas enfermedades y condiciones médicas en una muestra de médicos en Medellín - Colombia. CES Odontol. 2011;24(1):8. 